\title{
Vitamin A capsule distribution to control vitamin A deficiency in Indonesia: effect of supplementation in pre-school children and compliance with the programme
}

\author{
Rosnani Pangaribuan ${ }^{1,2, *}$, Jürgen G Erhardt ${ }^{2}$, Veronika Scherbaum ${ }^{2}$ and Hans K Biesalski ${ }^{2}$ \\ 'SEAMEO-TROPMED Regional Center for Community Nutrition, University of Indonesia, Jl. Salemba Raya 6, \\ Jakarta 10430, Indonesia: ${ }^{2}$ Institute of Biological Chemistry and Nutrition (140), University of Hohenheim, \\ Fruwirthstrasse 12, D-70599 Stuttgart, Germany
}

\section{Submitted 26 April 2002: Accepted 10 September 2002}

\begin{abstract}
Objective: The aim of this study was to evaluate the effectiveness of a widespread vitamin A supplementation programme and to describe indicators of compliance with the programme in Indonesia.

Design: Prospective cohort study. Children's anthropometric data were gathered at baseline (June 2000) and 4 months later (2 months after supplementation in August 2000). Serum retinol, haemoglobin, ferritin, $\alpha_{1}$-acid glycoprotein and C-reactive protein were measured at baseline and at follow-up. Caregivers of the children were interviewed using a questionnaire.

Setting: Semi-urban and rural areas of Semarang district, Central Java, Indonesia.

Subjects: Children $(\mathrm{n}=400)$ aged $1-5$ years.

Results: After the supplementation, the proportion of children with a low concentration of retinol decreased in recipients from 18.8 to $14.5 \%$. However, in non-recipients, the prevalence of vitamin A deficiency increased from 31.9 to $37.5 \%$, this prevalence being significantly higher than in recipients. A significant decrease occurred in the proportion of recipients with low ferritin (26.5 to 16.2\%) and haemoglobin (25.7 to $15.3 \%$ ), whereas the proportions did not show a significant change after supplementation for non-recipients. Modest linear growth was detected in recipients after supplementation but there was no effect on ponderal growth. The coverage rate of the supplementation in the study areas was $60 \%$. There was an association between compliance of the caregivers and their knowledge about the potential benefit of vitamin A supplementation, the place where sick children were taken and age of the children.

Conclusions: The vitamin A supplementation programme marginally decreased the proportion of vitamin A deficiency and had a marginal effect on the nutritional status of recipients. More than one micronutrient intervention is needed to increase the effectiveness of the supplementation programme. To increase compliance and coverage in the supplementation programme, nutrition communication and private healthcare practices need to be included in the programme.
\end{abstract}

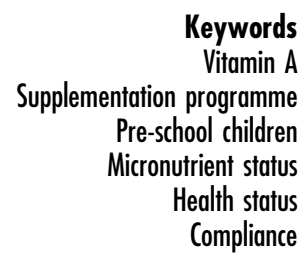

It is estimated that there are 254 million pre-school children in the world at risk of vitamin A deficiency and that $50 \%$ of these children are from Southeast Asia ${ }^{1}$. In addition, vitamin A deficiency world-wide may be responsible for more than a million deaths of young children annually and may cause blindness in more than half a million children ${ }^{2,3}$. One major strategy for preventing vitamin A deficiency in the community is through periodic delivery of oral doses of vitamin A to children of pre-school age.

Two decades ago, several countries in the region (Indonesia, Bangladesh, India and Vietnam) started universal supplementation with vitamin A capsules, which, according to the World Bank, is one of the most cost-effective forms of health intervention ${ }^{4}$. Substantial progress has been made in Indonesia in reducing the prevalence of explicit signs of vitamin A deficiency (xerophthalmia and night blindness), as determined by a national survey in $1992^{5}$. The overall prevalence of Bitot's spot in 15 provinces declined from 1.33 to $0.34 \%$ between $1977 / 78$ and 1992, while night blindness decreased from 0.84 to $0.13 \%$ in 12 provinces. However, sub-clinical vitamin A deficiency, as determined by serum retinol value, is still considerably high in this age group ${ }^{5-9}$. A recent study in Central Java showed that $15.4 \%$ of preschool children had very low serum retinol concentration 
$\left(<0.35 \mu \mathrm{moll}^{-1}\right)$ and $52 \%$ had low serum retinol concentration $\left(0.35-0.70 \mu \mathrm{moll}^{-1}\right)^{9}$. The prevalence of low serum retinol concentration (52\%) exceeded the World Health Organization (WHO) criterion $^{10}$ indicating vitamin A deficiency as a severe public health problem, which is $20 \%$ of values $<0.70 \mu \mathrm{moll}^{-1}$.

Many controlled studies have shown the inadequacy of supplementation with only a single nutrient (i.e. vitamin A supplementation) in controlling sub-clinical vitamin A deficiency, but there is limited information on the effectiveness of the vitamin A capsule distribution programme itself. The present study was designed to evaluate the effectiveness of the ongoing biannual (February and August) vitamin A capsule supplementation programme in increasing the micronutrient (especially vitamin A) and nutritional status of pre-school children, and to describe compliance with the programme in the province of Central Java, Indonesia.

\section{Materials and methods}

\section{Design and subjects}

The prospective cohort study was conducted from June to October 2000 in Ungaran sub-district (a semi-urban area) and Banyubiru sub-district (a rural area), which are both located in Semarang district, Central Java, Indonesia. One ward from Ungaran sub-district and two villages from Banyubiru sub-district were chosen as typical middle-class semi-urban and classic rural areas in this region. The total population in Semarang district was estimated to be 788000 in 1999 , with a population growth rate of $0.39 \%{ }^{11}$. The study basically describes one period of vitamin A supplementation that was carried out in August 2000 in each study area. The sample size was calculated using the formula for a community trial with $\alpha=0.05$ and $\beta=0.05$, and power index of 3.6. If the mean serum retinol difference between recipients and non-recipients ${ }^{12}$ was $0.15 \mu \mathrm{moll}^{-1}$, the sample size needed to assess the of effect of supplementation was 56 children for each group. Allowing for a high attrition rate, the sample size was increased by 30\%. For the two different sites (semi-urban and rural areas) a total number of 290 children would be required. Four hundred pre-school children (aged 12-60 months) were recruited during the study, and selection of the children was done using a random sampling technique from a list of children on a population data record of each area. The study was approved by the Committee on Health Research Ethics, Faculty of Medicine, University of Indonesia, Jakarta. Informed consent was obtained from the principal caregivers (mostly the mothers) of the children before the study started.

\section{Questionnaire-based interview}

The caregivers were interviewed at enrolment (June 2000), using a pre-coded questionnaire, to collect information on demographic factors, socio-economic condition, child's diet and breast-feeding and referral during child illnesses, using the guidelines of Gross et al. ${ }^{13}$. All questions regarding vitamin A, including knowledge of vitamin A, child's receiving the capsule in August 2000 and frequency of participating in the vitamin A programme, were asked 2 months after the supplementation (October 2000). The frequency of participation in the vitamin A programme was then categorised into three groups: regularly - children who fulfilled the vitamin A supplementation programme $50 \%$ or more according to their age; sometimes - children who fulfilled the vitamin A supplementation programme less than 50\% according to their age; and never - children who never participated in the vitamin A supplementation programme. A non-quantitative food-frequency questionnaire was administered for qualitative assessment of the adequacy of food intake. The approximate frequency with which the child had consumed certain food items during the preceding month was recorded into $\geq 1$ per day, $\geq 1$ per week, $\geq 1$ per month, $<1$ per month or never.

\section{Antbropometric assessment}

Children's anthropometric measurements were assessed at enrolment and again after 4 months (2 months after supplementation in August 2000). Weight was measured using a balance scale with a precision of $10 \mathrm{~g}$ (Seca, Hamburg, Germany). Length was measured to the nearest $0.1 \mathrm{~cm}$ using a standing height measurement microtoise (UNICEF, Copenhagen, Denmark) or a laying length board for children who were still below 2 years of age. Caregivers' weight and length were measured only at the beginning of the study.

\section{Biochemical measurements}

A blood sample $(\sim 400 \mu \mathrm{l})$ was collected by finger prick into a heparinised tube (Becton Dickinson, Franklin Lakes, NJ, USA) on the same day that anthropometric assessment was carried out. The haemoglobin concentration in the whole blood was determined in the field using a HemoCue (Ängholm, Sweden; haemoglobin-cyanide method). Serum retinol was analysed by high-pressure liquid chromatography according to the method of Erhardt et al. ${ }^{14}$. Ferritin, C-reactive protein (CRP) and $\alpha_{1}$-acid glycoprotein (AGP) were measured by standard enzymelinked immunosorbent assay procedures according to the manufacturer (DAKO, Hamburg, Germany). Both serum retinol and ferritin were analysed at the laboratory of the South East Asian Ministers of Education Organization/Tropical Medicine (SEAMEO-TROPMED), Jakarta, Indonesia, while CRP and AGP were analysed at the Institute of Biochemistry and Nutritional Science, University of Hohenheim, Stuttgart, Germany.

\section{Statistical analyses}

Data were checked for normal distribution using the Kolmogorov-Smirnov test of normality. Normally distributed variables are reported as means and standard 
deviation (SD), while medians ( 25 th -75 th percentile) are presented for variables that are not normally distributed. All data were pooled to determine the effect of vitamin A supplementation on the vitamin A and iron status of the recipient and non-recipient groups. The chi-square test was used to test differences in proportions while differences among groups were examined by analysis of variance (ANOVA) for normally distributed data and by the Kruskal-Wallis test for non-normally distributed data. To test differences between baseline and follow-up within the groups, we used the paired $t$-test or the Wilcoxon signed rank test for non-normally distributed data. The differences between recipients and non-recipients were tested using the independent $t$-test for normally distributed data or the Mann-Whitney $U$-test for non-normally distributed data. Plasma CRP and AGP concentrations were used as covariates in the analysis of retinol and ferritin to control for the effects of the acute phase response (analysis of covariance, ANCOVA).

The SPSS software package (Windows version 10.0; SPSS Inc., Chicago, IL) was used for all statistical analyses and a $P$-value of $<0.05$ was considered as significant. Weight and length were expressed as $Z$-scores using the National Center for Health Statistics (NCHS)/WHO reference data incorporated in the Epi-Info software (version 6.04; Centers for Disease Control, Atlanta, GA). Stunting, underweight and wasting were used as indices of malnutrition. Stunting was defined as a height-for-age $Z$-score (HAZ) below minus two standard deviations $(<-2 \mathrm{SD})$, underweight as weight-for-age $Z$-score
(WAZ) $<-2 \mathrm{SD}$ and wasting as weight-for-height $Z$-score (WHZ) $<-2 \mathrm{SD}$ of the NCHS medians. A blood haemoglobin level $<110 \mathrm{gl}^{-1}$ was used as a cut-off for defining anaemia, serum ferritin $<12 \mu \mathrm{gl}^{-1}$ was used as the cut-off for iron deficiency and serum retinol $<0.70 \mu \mathrm{moll}^{-1}$ was used as the cut-off for vitamin A deficiency.

\section{Results}

Of 400 pre-school children who were included in the baseline survey, only 305 complete datasets were available for anthropometric measurements, 303 for haemoglobin, 189 for retinol, and 186 for ferritin, CRP and AGP. Main reasons for dropping out included refusal of the caregiver because of time constraints or fear of blood donation, families leaving the area and sickness of the children. Children who dropped out did not differ from the other subjects in terms of anthropometric and biochemical values at baseline. The characteristics of the study children at baseline are shown in Table 1 . Children in the semiurban area seemed to be taller than children in the rural area $(P<0.05)$ and the prevalence of stunting $(\mathrm{HAZ}<-2)$ was also lower in the semi-urban as compared to the rural area $(P<0.001)$. Age and level of education of the caregivers were significantly different between rural and urban areas. Monthly household earnings were higher $(P<0.001)$ in the semi-urban than in the rural area, with medians ( 25 th -75 th percentile) of US\$46.6 (US\$32.3-80.0) and US\$33.3 (US\$20.0-60.0),

Table 1 Baseline characteristics of the study children

\begin{tabular}{|c|c|c|c|c|}
\hline & Semi-urban $(n=148)$ & Rural $(n=157)$ & $\begin{array}{l}\text { Recipients } \\
(n=183)\end{array}$ & $\begin{array}{c}\text { Non-recipients } \\
(n=122)\end{array}$ \\
\hline Age (months), mean \pm SD & $36.9 \pm 13.4$ & $36.6 \pm 13.3$ & $36.3 \pm 13.0$ & $37 \pm 13.9$ \\
\hline $12-24, n(\%)$ & $33(22.3)$ & $30(19.1)$ & $37(20.2)$ & $26(21.3)$ \\
\hline $24.1-36, n(\%)$ & $32(21.6)$ & $44(28.0)$ & $52(28.4)$ & $24(19.6)$ \\
\hline $36.1-48, n(\%)$ & $45(30.4)$ & $42(26.8)$ & $52(28.4)$ & $35(28.8)$ \\
\hline $48.1-60, n(\%)$ & $38(25.7)$ & $41(26.1)$ & $42(22.9)$ & 37 (30.3) \\
\hline \multicolumn{5}{|l|}{ Gender } \\
\hline Boys, $n(\%)$ & $75(50.7)$ & $77(49.0)$ & $91(49.7)$ & $61(50.0)$ \\
\hline Girls, $n(\%)$ & $73(49.3)$ & $80(51.0)$ & $92(50.2)$ & $61(50.0)$ \\
\hline Retinol $<0.7 \mu \mathrm{moll}^{-1}, n(\%)$ & $21(26.6)$ & $24(21.8)$ & $22(18.8)$ & $23(31.9) \dagger$ \\
\hline Haemoglobin $<110 \mathrm{gl}^{-1}, n(\%)$ & $44(30.1)$ & $34(21.7)$ & $47(25.7)$ & $31(25.8)$ \\
\hline Ferritin $<12 \mu \mathrm{gl}^{-1}, n(\%)$ & $16(19.5)$ & $2(1.9)^{\star \star \prime}$ & $31(26.5)$ & $20(28.2)$ \\
\hline Weight $(\mathrm{kg})$, mean $\pm S D$ & $12.3 \pm 2.28$ & $11.9 \pm 2.21$ & $12.1 \pm 2.2$ & $12.0 \pm 2.3$ \\
\hline Height $(\mathrm{cm})$, mean \pm SD & $90.7 \pm 8.65$ & $88.4 \pm 8.56^{\star}$ & $89.2 \pm 8.65$ & $89.9 \pm 8.73$ \\
\hline Stunted, $n(\%)$ & $22(14.9)$ & $53(35.8)^{\star \star}$ & $43(23.5)$ & $32(26.2)$ \\
\hline Underweight, $n(\%)$ & $37(25.0)$ & $46(29.3)$ & $44(24.0)$ & $39(32.0)$ \\
\hline Wasted, $n(\%)$ & $12(8.1)$ & $9(5.7)$ & $8(4.37)$ & $13(10.7) \dagger$ \\
\hline \multirow{2}{*}{\multicolumn{5}{|c|}{ Caregiver's formal education }} \\
\hline & & & & \\
\hline$\leq 6$ years schooling, $n(\%)$ & $61(41.2)$ & $106(67.5)^{\star \star}$ & $98(53.6)$ & $69(56.1)$ \\
\hline
\end{tabular}

SD - standard deviation.

For biochemical determinations, subject numbers were as follows: retinol $-n=79$ (semi-urban), $n=110$ (rural); haemoglobin $-n=$ 146 (semi-urban), $n=157$ (rural); ferritin $-n=82$ (semi-urban), $n=106$ (rural).

* Significantly different from semi-urban area, $P<0.05$ (t-test).

** Significantly different from semi-urban area, $P<0.001$ (chi-square test).

† Significantly different from recipients, $P<0.05$ (chi-square test).

$\ddagger$ Significantly different from recipients, $P<0.05$ ( $t$-test). 
respectively. The proportion of households in the semi-urban area with more than four family members was $53.4 \%$, as compared with $47.1 \%$ in the rural area.

\section{Haematological variables}

None of the children examined showed clinical signs of vitamin A deficiency. At baseline, there were no significant differences in retinol, haemoglobin or ferritin concentration between recipients and non-recipients of the vitamin A supplementation programme (Table 2). Retinol concentrations at baseline were not correlated with haemoglobin, ferritin and AGP (Spearman correlation coefficient); however, retinol was correlated with CRP $(r=-0.344, P<0.001)$.

After supplementation there were significant increases in retinol, haemoglobin and ferritin in recipients $(P<$ 0.05). However, only the concentration of retinol was significantly higher $(P<0.001$, ANCOVA controlling for CRP and baseline retinol) for recipients compared with non-recipients $\left(0.89 \pm 0.01\right.$ vs. $\left.0.78 \pm 0.01 \mu \mathrm{moll}^{-1}\right)$, with a mean increment of 0.05 (95\% confidence interval (CI) $0.02,0.07) \mu \mathrm{moll}^{-1}$ from baseline (Table 2). When data from a subgroup of children were analysed based on their initial nutritional status, there was a marginal supplementation effect in terms of haematological variables (Table 3 ).

The proportions of recipients and non-recipients with low concentrations of retinol at baseline and 2 months after supplementation are presented in Fig. 1. After supplementation, a significant decrease occurred only in the proportion of recipients with low ferritin (26.5 to $16.2 \% ; P<0.05)$ and haemoglobin (25.7 to $15.3 \%$; $P<0.05)$, whereas the proportions in the non-recipients did not change significantly after supplementation.

\section{Effect of supplementation on beight and weight}

Children's height and weight were measured at baseline and 4 months later ( 2 months after supplementation with the vitamin A capsule). Weight gain was not significantly different between recipients and non-recipients, with mean $( \pm \mathrm{SD})$ weight increments of $0.512 \pm 0.041 \mathrm{~kg}$ and $0.532 \pm 0.051 \mathrm{~kg}$, respectively. However, height gain was significantly higher $(P<0.001)$ among recipients, with a mean ( \pm SD) height increment of $2.57 \pm 0.062 \mathrm{~cm}$ compared with $2.21 \pm 0.076 \mathrm{~cm}$ in non-recipients. There were significant between-group differences in the increases in height based on age, gender and location of the children (Table 4). Recipients older than 48 months had greater height gain than the other age groups, with a mean $( \pm \mathrm{SD})$ significantly higher $(P<0.05$, ANOVA $)$ than the height increment of the 24-36 month and 36.1-48 month age groups; i.e. $2.92 \pm 0.20 \mathrm{~cm}, 2.37 \pm 0.12 \mathrm{~cm}$ and $2.52 \pm 0.13 \mathrm{~cm}$, respectively.

In children who were stunted at baseline, height gain and increase in HAZ were higher $(P<0.001)$ for recipients than for non-recipients between the baseline assessment and 4 months afterwards: the mean (95\% CI) change was 3.01 $(2.82,3.21) \mathrm{cm}$ in recipients and $2.23(1.98,2.46) \mathrm{cm}$ in nonrecipients for height, and $0.211(0.078,0.340)$ and 0.017 (1.98, 2.46), respectively, for HAZ (data not shown). On the other hand, for children who were underweight at baseline, there was no significant different in weight gain and WAZ between these two groups.

At baseline the prevalence of stunting, underweight and wasting in recipients was $23.5 \%, 24 \%$ and $4.4 \%$, respectively; for non-recipients it was $26.2 \%, 32 \%$ and $10.7 \%$, respectively. A decrease in the prevalence of stunting $(P<0.05)$ to $18.6 \%$ occurred in recipients, whereas the prevalence of malnutrition in non-recipients did not change significantly.

\section{Indicators for compliance}

Of all study children, $48.9 \%$ took the vitamin A capsule supplementation provided by the government regularly, $37 \%$ only sometimes and $8.2 \%$ never took it. During supplementation in August 2000, 60\% of the study children received the vitamin A capsule. The capsules were distributed by the midwives as district health centre staff or by community health volunteers. Table 5 shows some

Table 2 Concentrations of retinol, haemoglobin and ferritin at baseline and 4 months later (2 months after supplementation) in recipients and non-recipients

\begin{tabular}{|c|c|c|c|}
\hline & Baseline & $\begin{array}{l}4 \text { months } \\
\text { later }\end{array}$ & $\begin{array}{c}\text { Change } \\
\text { in mean }(95 \% \mathrm{Cl})\end{array}$ \\
\hline \multicolumn{4}{|l|}{ Retinol $\left(\mu \mathrm{mol} \mathrm{I}^{-1}\right)$, mean $\pm \mathrm{SD}$} \\
\hline Recipients $(n=117)$ & $0.85 \pm 0.02$ & $0.89 \pm 0.01$ & $0.05(0.02,0.07)^{\star}$ \\
\hline Non-recipients $(n=72)$ & $0.81 \pm 0.02$ & $0.78 \pm 0.01$ & $-0.05(-0.08,-0.01)^{*}$ \\
\hline \multicolumn{4}{|c|}{ Haemoglobin $\left(\mathrm{gl}^{-1}\right)$, median (range) } \\
\hline Recipients $(n=183)$ & $116.0(108.0-121.0)$ & $118.0(112.0-123.0)$ & $2.67(1.03,4.31) \dagger$ \\
\hline Non-recipients $(n=120)$ & $117.0(110.0-123.2)$ & $117.5(110.0-125.7)$ & $1.82(-0.20,3.84) \ddagger$ \\
\hline \multicolumn{4}{|l|}{ Ferritin $\left(\mu \mathrm{gl}^{-1}\right)$, mean $\pm S D$} \\
\hline Recipients $(n=115)$ & $18.7 \pm 9.4$ & $20.4 \pm 10.1$ & $1.73(0.17,3.30)^{\star *}$ \\
\hline Non-recipients $(n=71)$ & $17.2 \pm 7.2$ & $20.1 \pm 11.3$ & $2.87(0.91,4.83)^{\star}$ \\
\hline
\end{tabular}


Table 3 Micronutrient indicators at baseline and 4 months later (2 months after supplementation) for recipients who were stunted (HAZ $<-2 S D)$ or underweight (WAZ $<-2 S D$ ) and non-stunted or non-underweight at baseline

\begin{tabular}{lllll}
\hline & \multicolumn{1}{c}{$\begin{array}{c}\text { Stunted } \\
\text { recipients }\end{array}$} & \multicolumn{1}{c}{$\begin{array}{c}\text { Underweight } \\
\text { recipients }\end{array}$} & \multicolumn{1}{c}{$\begin{array}{c}\text { Non-stunted } \\
\text { recipients }\end{array}$} & $\begin{array}{c}\text { Non-underweight } \\
\text { recipients }\end{array}$ \\
\hline Retinol $\left(\mu\right.$ mol I $^{-1}$ ), mean $\pm \mathrm{SD}$ & $(n=31)$ & $(n=30)$ & $(n=86)$ & $(n=87)$ \\
$\quad$ Baseline & $0.84 \pm 0.22$ & $0.82 \pm 0.19$ & $0.86 \pm 0.21$ & $0.87 \pm 0.22$ \\
4 months later & $0.84 \pm 0.27$ & $0.89 \pm 0.26$ & $0.86 \pm 0.21$ & $0.85 \pm 0.22$ \\
Change, mean $(95 \% \mathrm{Cl})$ & $0.002(-0.06,0.07)$ & $0.048(-0.02,0.12)$ & $-0.006(-0.05,0.04)$ & $-0.02(-0.06,0.02)$ \\
Haemoglobin $\left(\mathrm{gl}^{-1}\right)$, median (range) & $(n=43)$ & $(n=45)$ & $(n=140)$ & $(n=138)$ \\
Baseline & $116.0(110.0-121.0)$ & $115.0(107.5-121.5)$ & $116.0(107.0-122.0)$ & $116.0(107.2-121.0)$ \\
4 months later & $120.0(113.0-126.0)^{\star}$ & $117.0(112.0-121.0)$ & $118.0(112.0-123.0)^{\star}$ & $118.0(113.0-124.7)^{\star}$ \\
Change, mean $(95 \% \mathrm{Cl})$ & $3.76(0.10,7.37)$ & $2.50(-0.70,5.74)$ & $2.43(0.66,4.20)$ & $2.82(0.98,4.63)$ \\
Ferritin $\left(\mu \mathrm{gl}^{-1}\right)$, mean $\pm \mathrm{SD}$ & $(n=28)$ & $(n=27)$ & $(n=87)$ & $(n=88)$ \\
Baseline & $20.0 \pm 8.10$ & $17.9 \pm 7.92$ & $18.3 \pm 9.79$ & $18.9 \pm 9.84$ \\
4 months later & $22.5 \pm 9.57$ & $18.1 \pm 7.68$ & $19.7 \pm 10.3$ & $21.1 \pm 10.7 \dagger$ \\
Change, mean $(95 \% \mathrm{Cl})$ & $2.52(-0.45,5.50)$ & $0.25(-2.09,2.61)$ & $1.48(-0.34,3.04)$ & $2.21(0.31,4.12)$ \\
\hline
\end{tabular}

HAZ- height-for-age Z-score; WAZ - weight-for-age Z-score; SD - standard deviation, Cl - confidence interval.

* Significantly different from baseline, $P<0.05$ (Wilcoxon test).

† Significantly different from baseline, $P<0.05$ (paired $t$-test).

indicators of compliance with the vitamin A capsule supplementation programme in August 2000 in semiurban and rural areas. A range of caregiver characteristics, such as age, nutritional status and their relationship to the child, showed no influence on compliance with the supplementation programme. In rural areas, caregivers who complied with the programme seemed to be older and better educated than those who did not comply. Twenty-six per cent of the children from rural areas were looked after by a family member other than their mother, with $14 \%$ of the caregivers being more than 45 years old.

In the semi-urban area, mothers who practised exclusive breast-feeding for 4 months participated more than those who started to give supplementary foods earlier than 4 months to their children. Overall, 57\% of the mothers practised exclusive breast-feeding. Over $40 \%$ of the children were breast-fed until they reached 2 years of age. The percentage of semi-urban children who were older than 4 years and did not get a vitamin A capsule was higher in non-recipients $(34.8 \%, P<0.05)$ than in recipients (18.3\%).
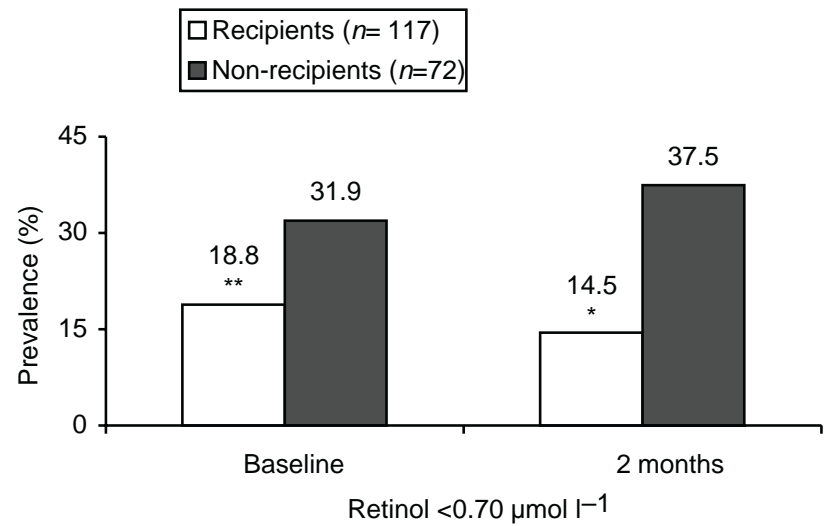

Fig. 1 Proportion of low retinol at baseline and 2 months after supplementation with a vitamin A capsule. Significant difference between recipients and non-recipients: ${ }^{*}, P<0.001 ;{ }^{*}, P<0.05$ (chi-square test)
In the semi-urban area, more caregivers who usually took their sick children to private doctors did not participate in the supplementation programme. The percentage of caregivers who utilised a community health centre or midwives' practice in the rural area was significantly higher $(82.2 \%, P<0.001)$ than in the semiurban area (60.8\%). In both areas caregivers with a better understanding of the value of vitamin A supplementation complied more with the programme.

\section{Determinants of frequency of participation in the vitamin A capsule supplementation programme}

Using binary logistic regression models determinants of frequency of participation in the vitamin A capsule supplementation programme were developed. Dependent variables were entered as dichotomous $(0=$ sometimes; $1=$ regularly). Variables that were found to be significantly associated in bivariate analysis were then re-entered in the model. Four variables were found to be statistically significant: participation in the vitamin A capsule programme in August $2000 \quad(P=0.001)$, caregiver's knowledge about the benefit of vitamin A supplementation for the child's health $(P=0.001)$,

Table 4 Adjusted mean height increments for recipients and nonrecipients during the 4-month follow-up period (2 months after supplementation). All values are mean \pm standard error of the mean and adjusted for baseline weight, height, age and sex

\begin{tabular}{lcc}
\hline & \multicolumn{1}{c}{$\begin{array}{c}\text { Recipients } \\
(n)\end{array}$} & $\begin{array}{c}\text { Non-recipients } \\
(n)\end{array}$ \\
\hline $\begin{array}{l}\text { Age group (months) } \\
\text { 12.0-36.0 }\end{array}$ & $2.88 \pm 0.09(89)^{\star *}$ & $2.46 \pm 0.12(50)$ \\
$\begin{array}{l}36.1-60.0 \\
\text { Gender }\end{array}$ & $2.32 \pm 0.08(94)^{\star}$ & $1.99 \pm 0.09(72)$ \\
$\quad$ Boys & $2.56 \pm 0.08(91)^{\star \star}$ & $2.26 \pm 0.10(61)$ \\
$\quad$ Girls & $2.59 \pm 0.09(92)^{*}$ & $2.16 \pm 0.11(61)$ \\
Location & & \\
$\quad$ Semi-urban & $2.48 \pm 0.10(82)^{\star *}$ & $2.18 \pm 0.11(66)$ \\
Rural & $2.62 \pm 0.07(101)^{*}$ & $2.27 \pm 0.10(56)$ \\
\hline
\end{tabular}

Significantly different from non-recipients: *, $P<0.01$; **, $P<0.05$ (analysis of variance). 
Table 5 Characteristics of the caregivers and households in semi-urban and rural areas, according to compliance and non-compliance with the vitamin A capsule supplementation programme in August 2002. All values are given as $n(\%)$, except where stated otherwise

\begin{tabular}{|c|c|c|c|c|c|c|}
\hline & \multicolumn{3}{|c|}{ Semi-urban } & \multicolumn{3}{|c|}{ Rural } \\
\hline & $\begin{array}{c}\text { Compliance } \\
(n=82)\end{array}$ & $\begin{array}{c}\text { Non-compliance } \\
(n=66)\end{array}$ & $P$ & $\begin{array}{c}\text { Compliance } \\
(n=101)\end{array}$ & $\begin{array}{c}\text { Non-compliance } \\
(n=56)\end{array}$ & $P$ \\
\hline \multicolumn{7}{|l|}{ Caregiver } \\
\hline Age (years), mean $\pm S D$ & $31.7 \pm 8.5$ & $30.8 \pm 6.4$ & NS & $35.0 \pm 11.0$ & $31.9 \pm 10.0$ & NS \\
\hline $\mathrm{BMI}<18.5 \mathrm{~kg} \mathrm{~m}^{-2}$ & $11(13.4)$ & $8(12.1)$ & NS & $14(13.9)$ & $6(10.7)$ & NS \\
\hline Mother of the index child & $71(86.6)$ & $58(87.9)$ & NS & $73(72.3)$ & $43(76.8)$ & NS \\
\hline$<6$ years of schooling & $35(42.7)$ & $26(39.4)$ & NS & $55(54.5)$ & $43(76.8)$ & 0.020 \\
\hline \multicolumn{7}{|l|}{ Feeding practices } \\
\hline Duration of breast-feeding $>6$ months & $64(78)$ & $51(77.3)$ & NS & $71(62.3)$ & $43(76.8)$ & NS \\
\hline Complementary food given $>4$ months & $53(64.6)$ & $31(47)$ & 0.024 & $55(54.4)$ & $35(62.5)$ & NS \\
\hline \multicolumn{7}{|l|}{ Referral when the child was sick } \\
\hline Community healthcare centre or community midwife & $59(72)$ & $31(47)$ & & $81(80.2)$ & $48(85.7)$ & \\
\hline Private doctor & $23(28)$ & $35(53)$ & 0.002 & $20(19.8)$ & $8(14.3)$ & NS \\
\hline \multicolumn{7}{|c|}{ Caregiver's knowledge about health benefit of vitamin A } \\
\hline Right answers & $71(86.6)$ & $47(71.2)$ & & $63(62.4)$ & $25(44.6)$ & \\
\hline Don't know/no answers & $11(13.4)$ & $19(28.8)$ & 0.021 & $38(37.6)$ & $31(55.4)$ & 0.032 \\
\hline \multicolumn{7}{|c|}{ Frequency of participating in vitamin A supplementation programme* } \\
\hline Regularly & $53(69.7)$ & $23(34.8)$ & & $60(59.4)$ & $13(23.2)$ & \\
\hline Sometimes & $23(28)$ & $31(47)$ & 0.001 & 33 (32.7) & $26(46.4)$ & 0.001 \\
\hline Household member $>4$ persons & $44(53.7)$ & $31(53)$ & NS & $41(40.6)$ & $33(58.9)$ & 0.027 \\
\hline
\end{tabular}

BMI - body mass index; SD - standard deviation; NS - not significant.

${ }^{*}$ Regularly defined as fulfilling the vitamin A supplementation programme $50 \%$ or more according to the child's age; sometimes defined as fulfilling the programme less than $50 \%$ according to the child's age.

the place where the sick child was taken for treatment $(P=0.005)$ and the age of the index child $(P=0.001)$.

\section{Discussion}

Micronutrient deficiencies in pre-school children were high in the study area, with prevalences of low concentrations of retinol, haemoglobin and ferritin of $23.8 \%, 27.1 \%$ and $25.7 \%$, respectively. In general such a high proportion of micronutrient malnutrition is not exceptional in Indonesia. Although the percentage prevalences of anaemia and vitamin A deficiency in the study area were less than the estimated national prevalences, which are $40 \%$ for anaemia ${ }^{15}$ and $50 \%$ for vitamin A deficiency ${ }^{5}$, the percentages still reached levels of public health significance.

The findings of the present study indicated that administration of the vitamin A capsule supplementation programme set up by the government of Indonesia improved only some haematological variables both for malnourished and well nourished children. It also showed that, even after receiving a large dose of vitamin A, a significant number of children in the recipients group remained vitamin A-deficient. The reduction in vitamin A deficiency was $23 \%$ in recipients, whereas an increased deficiency of $17 \%$ was detected in non-recipients. The vitamin A supplementation also modestly improved overall linear growth but had no effect on ponderal growth. Stunted children also benefited in linear growth from vitamin A supplementation; however, underweight children showed marginal benefits in weight increments.
This finding suggests that it would be advisable for the government of Indonesia to improve strategies in combating vitamin A deficiency among pre-school children. A single micronutrient supplementation programme alone is not sufficient to correct vitamin A deficiency in a large proportion of the children, especially undernourished children, where other additional micronutrient deficiencies coexist ${ }^{16-18}$. Some controlled studies in developing countries have shown that a combined iron-zinc-vitamin A supplementation more effectively corrected the vitamin $\mathrm{A}$ and zinc status and reduced anaemia, where the coexistence of marginal vitamin A deficiency with zinc and iron deficiency was common $^{19-22}$. The habitual Indonesian diet, which is based mainly on rice that contains little zinc but a relatively high amount of phytate ${ }^{23}$, may also explain the high prevalence of zinc deficiency in this population. In Guatemala, children who were supplemented with both vitamin A and iron showed a significant increase in ferritin and the highest increases in retinol, haemoglobin, serum iron and percentage transferrin saturation, compared with those receiving vitamin A or iron alone ${ }^{19}$. A study in Vietnam, where the children were supplemented with retinol, iron and zinc, showed promising increases in retinol and haemoglobin concentrations and reductions in the prevalence of low retinol concentration and anaemia $^{20}$. Studies in Mexico and Bangladesh demonstrated again that only combined vitamin A and zinc or iron supplementation, or both, successfully reverted the deficiency in vitamin A-deficient children $^{21,22}$. The findings of all these studies demonstrate 
that vitamin A status can be improved more effectively by a combined application of vitamin A with zinc and iron.

Despite an increase in biochemical nutritional indicators with combination supplementation, growth velocity did not show significant results in either the Vietnam or the Bangladesh study. Thu et al. concluded that linear growth of the most growth-retarded part of the population was positively affected by a vitamin A-zinc-iron supplementation, but the average value of the whole population was not significantly affected ${ }^{20}$. In Bangladesh, a vitamin Azinc supplementation trial failed to improve growth velocity in a subgroup of malnourished children over a 6-month follow-up period ${ }^{22,24}$. This supports the findings of several studies that, in addition to micronutrients, a sufficient intake of macronutrients (protein, fat, carbohydrate and energy) is also necessary for adequate growth in children.

In the study population, $46.9 \%$ of semi-urban and $53.1 \%$ of rural households lived below the poverty line ${ }^{25}$. At the moment, approaches like dietary diversification to improve the micronutrient intakes of children are not feasible, because the monetary crisis that hit Indonesia in mid-1997 has led to increases in food prices of up to 200$300 \%{ }^{26,27}$. The increased food prices have worsened the household food security situation. On average, more than $70 \%$ of the children consumed vitamin A-rich foods only once or more per week, these foods being basically of plant origin in both areas of the study population. Animal products such as meat, fish or liver were consumed less frequently especially in rural areas. This pattern of intake, combined with the relatively monotonous diet of the children and recent debate on the reduced bioavailability of vitamin A from plant sources ${ }^{28}$, brings up important questions on the ability of these diets to meet the vitamin A requirements of children without the inclusion of animal products. Therefore, food fortification to combat vitamin A deficiency seems preferable for the current situation. Some studies have shown that fortification of condiments such as monosodium glutamate ${ }^{29}$, sugar ${ }^{30}$ and wheat ${ }^{31}$ with vitamin A considerably improved vitamin A status. However, vitamin A-fortified monosodium glutamate in Indonesia was not favourable since it changed the colour and increased the price of the product. Fortification of food with vitamin A is still a rare practice in Indonesia. It is important that adding micronutrients to the widely and regularly consumed foods does not increase the cost and change the appearance, colour, texture or organoleptic properties of the products.

It is also shown that a lack of understanding about the importance of vitamin A and the need to take regular vitamin A supplementation until the children reach 5 years of age may have influenced compliance. The awareness level especially of less educated caregivers should be improved through nutrition communication programmes. Among all caregivers who participated in the supplementation programme, only $35.4 \%$ reported that the midwives or health volunteers informed them about the health advantage of the vitamin A capsule. Of all the study population in both semi-urban and rural settings, $28.2 \%$ utilised private health services. In addition, private doctors could help increase the coverage of vitamin A supplementation as additional channels of a country-wide policy of biannual capsule distribution in addition to community health centre staff (i.e. community midwives) or health volunteers. The coverage of the supplementation in this study was about the same as the overall national coverage in $1993^{32}$ : 60\% and 54\%, respectively.

We conclude that in a country like Indonesia, which has a high level of vitamin A and other micronutrient deficiencies and an insecure economic situation, it is important to pursue an integrated approach that covers more than one micronutrient as a short-term measure and also to consider fortification as a medium-term strategy in order to augment the quality of life of Indonesian children. Current tendencies towards private doctors' practices could improve access to supplementation of pre-school children when they are in contact with this type of primary care service. Supplementation programmes should be prioritised for marginally malnourished children, and dietary diversification should be relied on as the long-term preventive strategy against malnutrition for the whole population.

\section{Acknowledgements}

This work was supported by the Neys van Hoogstraten Foundation, The Netherlands and Deutscher Akademischer Austauschdienst, Germany, for which we would like to express gratitude. Our sincere appreciation goes to the caregivers and their children, the sub-district office staff and fieldworkers, the health centres and their staff and the blood analysis team for participating in this study. The authors thank Erika Wasito, and Elvina Karyadi at SEAMEO-TROPMED Regional Center for Community Nutrition, University of Indonesia, for her valuable comments on statistical analysis.

\section{References}

1 World Health Organization (WHO). Global Prevalence of Vitamin A Deficiency. Geneva: WHO, 1995.

2 Humphrey JH, West KP Jr, Sommer A. Vitamin A deficiency and attributable mortality among under-5-year-olds. Bull. World Health Org. 1992; 70(2): 225-32.

3 Sommer A, Tarwotjo I, Hussaini G, Susanto D. Increased mortality in children with mild vitamin A deficiency. Lancet 1983; 2(8350): 585-8.

4 Sommer A, West KP. Vitamin A Deficiency, Health, Survival and Vision. New York: Oxford Press, 1996.

5 Muhilal, Tarwotjo I, Kodyat B, Herman S, Permaesih D, Karyadi D, et al. Changing prevalence of xerophthalmia in Indonesia, 1977-1992. Eur. J. Clin. Nutr. 1994; 48(10): 708-14.

6 Tanumihardjo SA, Permaesih D, Dahro AM, Rustan E, Muhilal, Karyadi D, et al. Comparison of vitamin A status 
assessment techniques in children from two Indonesian villages. Am. J. Clin. Nutr. 1994; 60(1): 136-41.

7 Tanumihardjo SA, Suharno D, Permaesih D, Muherdiyantiningsih, Dahro AM, Muhilal, et al. Application of the modified relative dose response test to pregnant Indonesian women for assessing vitamin A status. Eur. J. Clin. Nutr. 1995; 49(12): 897-903

8 Dibley MJ, Sadjimin T, Kjolhede CL, Moulton LH. Vitamin A supplementation fails to reduce incidence of acute respiratory illness and diarrhea in preschool-age Indonesian children. J. Nutr. 1996; 126(2): 434-42.

9 Hadi H, Stoltzfus RJ, Dibley MJ, Moulton LH, West KP Jr, Kjolhede CL, et al. Vitamin A supplementation selectively improves the linear growth of Indonesian preschool children: results from a randomized controlled trial. $A m$. J. Clin. Nutr. 2000; 71(2): 507-13.

10 World Health Organization (WHO). Indicators for Assessing Vitamin A Deficiency and Their Application in Monitoring and Evaluating Intervention Programmes. Geneva: WHO, 1996.

11 Bureau of Statistik Semarang District. Population Census. Semarang: 1999.

12 Bloem MW, Wedel M, van Agtmaal EJ, Speek AJ, Saowakontha S, Schreurs WH. Vitamin A intervention: short-term effects of a single, oral, massive dose on iron metabolism. Am. J. Clin. Nutr. 1990; 51(1): 76-9.

13 Gross R, Kielmann A, Korte R, Schoeneberger H, Schultink W. Guidelines for Nutrition Baseline Surveys in Communities. Bangkok: South East Asian Ministers of Education Organization/Tropical Medicine (SEAMEO-TROPMED) and Deutsche Gesellschaft für Technische Zusammenarbeit, 1997.

14 Erhardt JG, Heinrich F, Biesalski HK. Determination of retinol, antioxidant vitamins and homocysteine in skin puncture blood. Int.J. Vitam. Nutr. Res. 1999; 69(5): 309-14.

15 World Health Organization (WHO). The South-East Asia Nutrition Research-cum-Action Network Report of the Fifth Meeting, Thailand, June 1999.

16 Mahalanabis D. Breast feeding and vitamin A deficiency among children attending a diarrhoea treatment centre in Bangladesh: a case-control study. Br. Med. J. 1991; 303(6801): 493-96.

17 Rahman MM, Mahalanabis D, Wahed MA, Islam MA, Habte D. Administration of $25,000 \mathrm{IU}$ vitamin A doses at routine immunisation in young infants. Eur. J. Clin. Nutr. 1995; 49(6): 439-45.

18 Rahman MM, Mahalanabis D, Alvarez JO, Wahed MA, Islam MA, Habte D, et al. Acute respiratory infections prevent improvement of vitamin A status in young infants supplemented with vitamin A. J. Nutr. 1996; 126(3): 628-33.

19 Mejia LA, Chew F. Hematological effect of supplementing anemic children with vitamin A alone and in combination with iron. Am. J. Clin. Nutr. 1988; 48(3): 595-600.

20 Thu BD, Schultink W, Dillon D, Gross R, Leswara ND, Khoi $\mathrm{HH}$. Effect of daily and weekly micronutrient supplementation on micronutrient deficiencies and growth in young Vietnamese children. Am. J. Clin. Nutr. 1999; 69(1): 80-6.

21 Munoz EC, Rosado JL, Lopez P, Furr HC, Allen LH. Iron and zinc supplementation improves indicators of vitamin A status of Mexican preschoolers. Am. J. Clin. Nutr. 2000; 71(3): 789-94.

22 Rahman MM, Wahed MA, Fuchs GJ, Baqui AH, Alvarez JO Synergistic effect of zinc and vitamin A on the biochemical indexes of vitamin A nutrition in children. Am. J. Clin. Nutr 2002; 75(1): 92-8.

23 Tuntawiroon M, Sritongkul N, Rossander-Hulten L, Pleehachinda $\mathrm{R}$, Suwanik $\mathrm{R}$, Brune $\mathrm{M}$, et al. Rice and iron absorption in man. Eur. J. Clin. Nutr. 1990; 44(7): 489-97.

24 Rahman MM, Tofail F, Wahed MA, Fuchs GJ, Baqui AH, Alvarez JO. Short-term supplementation with zinc and vitamin A has no significant effect on the growth of undernourished Bangladeshi children. Am. J. Clin. Nutr. 2002; 75(1): 87-91.

25 Menno P, Suryahadi A, Sumarto S, Pritchett L. Measurement of Poverty in Indonesia, 1996, 1999 and Beyond. Jakarta, Indonesia: SMERU, 2000.

26 Sumarto S, Surhayadi A, Widyanti W. Designs and Implementation of the Indonesian Social Safety Net Programs: Evidence from the JPS Module in the 1999 SUSENAS. Jakarta, Indonesia: The SMERU Research Institute, 2001.

27 World Bank. Social Crisis in East Asia. Indonesia and Poverty [online]. Available at http://www.worldbank.org, 1999.

28 de Pee S, West CE. Dietary carotenoids and their role in combating vitamin A deficiency: a review of the literature. Eur. J. Clin. Nutr. 1996; 50(Suppl. 3): S38-53.

29 Muhilal, Murdiana A, Azis I, Saidin S, Jahari AB, Karyadi D. Vitamin A-fortified monosodium glutamate and vitamin A status: a controlled field trial. Am. J. Clin. Nutr. 1988; 48(5): 1265-70.

30 Arroyave G, Mejia LA, Aguilar JR. The effect of vitamin A fortification of sugar on the serum vitamin A levels of preschool Guatemalan children: a longitudinal evaluation. Am. J. Clin. Nutr. 1981; 34(1): 41-9.

31 Solon FS, Klemm RD, Sanchez L, Darnton-Hill I, Craft NE, Christian $\mathrm{P}$, et al. Efficacy of a vitamin A-fortified wheat-flour bun on the vitamin A status of Filipino schoolchildren. Am. J. Clin. Nutr. 2000; 72(3): 738-44.

32 Seidel RE. Strategies for Promoting Vitamin A. Production, Consumption and Supplementation. Four Case Studies. Washington, DC: The Academy for Educational Development, 1996. 